Conclusions In areas with high rates of $\mathrm{TB}$ in a district a dedicated district service seems an effective way to see patients within a Mutidiscliplinary Team and allows good liason with Adult TB team. The setting up of networks for Paediatric TB may encourage this set up with discussion of active cases with tertiary infectious disease specialists while maintaining good local supportive supervision and deliver of care.

\section{G590(P) THE PREVALENCE OF HYPOCALCEMIA IN CHILDREN WITH DENGUE INFECTION: A 1 YEAR CROSS-SECTIONAL STUDY}

Miss Singh, Mr Kamble. Paediatrics, JNMC, Belagavi, India

10.1136/archdischild-2020-rcpch.507

Introduction According to WHO, Dengue is fast emerging pandemic-prone viral disease affecting mainly urban poor areas in tropical and subtropical countries. There is an urgent need for early recognition and prompt treatment in order to limit the morbidity and mortality. One of the important electrolyte disturbance documented in critical phase of severe dengue is hypocalcaemia. Studies have linked calcium with the immune response and severity of infection of dengue virus.

Objectives

- To study the prevalence of hypocalcaemia in children suffering from dengue infection.

- To study the association between the degree of hypocalcaemia and the severity of the illness.

Methods and Material This study is a one-year cross sectional observational study, conducted in a tertiary care hospital. 100 subjects aged 1 month to 18 years suffering from dengue were included in the study. The subjects were classified as per 2009 WHO classification into Dengue fever without warning sign, Dengue fever with warning signs (DWS) and Severe dengue (SD). Ionic calcium and other biochemical parameters were done for all the subjects within 24 hours of admission. The clinical and biochemical data was coded and analyzed.

Results The mean age of the study population was $9.65 \mathrm{yr}$ with $58 \%$ males and $42 \%$ females. The prevalence of hypocalcemia was found to be $59.0 \%$. The mean $\mathrm{iCa}$ was 1.05 $\mathrm{mmol} / \mathrm{L}$. The study showed that $11.7 \%$ subjects with dengue without warning signs, $83.7 \%$ subjects of DWS and $100 \%$ of the subjects of SD had hypocalcaemia. It was seen that level of $\mathrm{iCa}$ is lowest in severe dengue $(\mathrm{p}<0.001)$.

$\begin{aligned} & \text { Abstract } \\
& \text { iCa }\end{aligned}$
\begin{tabular}{lllllll}
\hline Variables & Table 1 & Distribution of subjects with respect to \\
\hline iCa (mmol/L) & Classification of dengue & N & Mean iCa & Std. Dev & F & Sig. \\
& Dengue with warning signs & 43 & 1.05 & 0.06 & & \\
& Severe dengue & 19 & 0.98 & 0.05 & & \\
\hline
\end{tabular}

Conclusion This study proves the association of the hypocalcaemia with the severity of dengue infection in the paediatric population and potentiates the use of ionic calcium as a biochemical marker to detect severe dengue infection early.

\section{G591(P) ARE WE LOSING THE BATTLE AGAINST INFECTIONS? AN AUDIT ON ANTIMICROBIAL RESISTANCE}

${ }^{1} \mathrm{~L}$ Rehman, ${ }^{2} \mathrm{M}$ Kamal, ${ }^{1} \mathrm{~F}$ Neenan, ${ }^{3} \mathrm{M}$ Hussain, ${ }^{1} \mathrm{M}$ Shahid. ${ }^{1}$ Paediatrics Department, Portiuncula University Hospital, Ballinasloe, Ireland; ${ }^{2}$ Paediatric Emergency Department, Tallaght University Hospital, Dublin, Ireland; ${ }^{3}$ Department of Children and Young People, North Cumbria Integrated Care, Whitehaven, UK

\subsection{6/archdischild-2020-rcpch.508}

Aim To analyse the practice of prescribing outpatient antibiotics and check adherence to antimicrobial guidelines in the Paediatric Emergency Department (PED) of a university hospital. Method All children, prescribed antibiotics before discharge from PED were included. Pre-intervention, 55 charts in between Feb-April 2019 were audited retrospectively for prescribing 1)Correctly indicated antibiotics against certain infections based on clinical judgement and/or investigations, 2) Correct choice, 3)Duration and 4)Dose against standards as

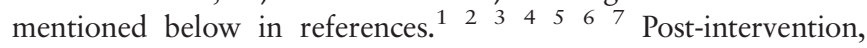
30 charts were audited between May-July 2019 to re-check adherence to recommended standards. Standards were redefined and implemented for common infections encountered in PED by physicians as per results of the audit. Clinical judgment was deemed optimal if it followed the standard. ${ }^{1} 2334567$

Results Pre interventions, only $56 \%$ of antibiotics were correctly indicated for certain infections. Post intervention, 96\% were correctly indicated, resulting in an improvement of $20 \%$. Regarding prescribing the correct type of antimicrobials, antibiotic guidelines were adhered to $84 \%$ of the time. This rose to $100 \%$ post-intervention. Of the antibiotics prescribed, $41 \%$ of outpatients were prescribed an insufficient dose which declined to $3 \%$ after intervention.

Conclusion Despite, substantially reduced mortality from infectious diseases by advances in antimicrobials, resistance is growing at an alarming rate. This rise in antimicrobial resistance is one of the greatest potential threats to human health at global levels with serious consequences for public health, animal health and welfare. ${ }^{8} 9$ Outpatient antimicrobial scripts are being written in the PED on a daily basis by junior doctors who rotate from different specialities every six months. Also, factors such as sub-optimal clinical judgement, parental reassurance and heavy workload in PED might contribute to excessive prescription. Our audit prompted us to make standards clear for all NCHDS. Our interventions reduced the margin of error substantially.

\section{REFERENCES}

1. Childhood Pneumonia, Faculty of Paediatrics (RCPI), HSE Guidelines, Feb 2014

2. Urinary Tract Infection, Faculty of Paediatrics (RCPI), HSE Guidelines

3. Acute Otitis Media, Faculty of Paediatrics (RCPI), HSE Guidelines

4. Sore throat (acute): antimicrobial prescribing, National Institute for Health and Care Excellence(NICE) guidelines, 2018

5. Our Lady's Children Hospital Formulary, OLCHC/TSCUH ANTIBIOTIC GUIDELINES

6. Galway Antimicrobial Prescribing Principles(GAPP)

7. BNF For Children 2019

8. https://health.gov.ie/blog/publications/irelands-national-action-plan-on-antimicrobial-resistance-2017-2020/

9. https://www.who.int/antimicrobial-resistance/global-action-plan/en/

\section{G592(P) DISSEMINATED NEONATAL HERPES: THE DEADLY MASQUERADER}

V Subbaraju, S Pradhan, P Nair. Paediatric Department, Bedford Hospital NHS Trust, Bedford, UK

10.1136/archdischild-2020-rcpch.509 